\title{
大型送風機用羽根車の微小亀裂原因調査と構造変更*
}

\author{
夈田克也*1, 大竹 雅 浩*2$$
\text { 岩 原 光 男*3, 長 松 昭 男*4 }
$$

\section{An Investigation of the Small Crack and Structural Modification for a Big Impeller} \\ Katsuya KUMEDA, Masahiro OHTAKE, \\ Mitsuo IWAHARA*5 and Akio NAGAMATSU \\ ${ }^{* 5}$ Graduate School of Mechanical Engineering, Hosei University, \\ 3-7-2 Kajino-cho, Koganei-shi, Tokyo, 184-8584 Japan

\begin{abstract}
The crack arose during actual operation, in an impeller of large-sized blower, at the joint part of the main board and blade. For the purpose to clarify this phenomenon, dynamic analysis and static analysis using the finite element method were performed. The analysis results showed that the cause of a crack of impeller is the stress which occurs owing to the deformation of the side board by centrifugal force. This deformation is wave like one which is same pitch as blade. Then, the structural modification by pseudo-inverse method was performed for the purpose of stress reduction. In this case, designer does not want the minimum weight optimum design but the minimum modification design. Pseudo-inverse method may modify the structure with the minimum distance in the design variable space to satisfy the stress restriction. Some cases are tried. When the design variables were 3 main parts thicknesses, those are main board, side board and blade, practical solution is deduced for 8 calculations to satisfy the stress limit with $10 \%$ weight increase.
\end{abstract}

Key Words: Optimum Design, Blower, Finite Element Method, Structural Analysis

\section{1. 緒言}

現在, 様々な機械が設計・開発・生産され，実際に 稼動している. 稼働中の不具合を防ぐために, 設計時 に強度計算が行われ, 強度不足であると判断されれば 改良されてから実用に供される.しかし, 設計時の強 度計算における仮定が正しくない場合, 予想外の応力 が発生し, 不具合の原因となることがある. 設計者は 不具合を解消するために様々な対策を行い，それが経 験として企業内に構築される.

本研究は，実稼動中の大型送風機用羽根車において， 側板とブレードとの結合部に検出された微小亀裂の原

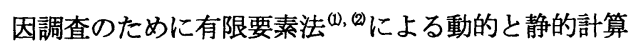
を行う. 計算結果, 実験結果と設計者からの情報によ り，亀裂発生現象を明らかにする.

対象構造物の形状・寸法が決まれば, 有限要素法を 実行することにより, 要求された特性を満足するかど うかを予測できる. 近年, 形状・寸法の設計や問題解 決のための修正方法の決定などの対策案提示を行うた

\footnotetext{
* 原稿受付 2006 年 9 月 20 日.

*1 准員, 法政大学大学院機械工学専攻( 1 184-8584 小金井市 梶尾町 3-7-2)

*2 日野自動車 (株) (画 191-8660 日野市日野台 3-1-1).

*3 正員, 法政大学工学部機械工学科.

*4 正員, 名誉員, 法政大学工学部機械工学科.

E-mail : iwahara@k.hosei.ac.jp
}

めに, 最適設計手法が適用され始めている. しかし, 最適設計手法をこのような実際の問題に適用するには, 以下の困難がある.まず，制約条件の数が多いことで ある. 実稼動中の各部の応力だけでなく, 振動現象, 機械起動時の負荷に耐えること, 高温・腐食雾囲気に 耐えること, 機械としての性能を確保すること, 生産 コストを上昇させないなどの全ての制約条件を考慮し ての最適設計手法適用は困難である. 次に, 企業内に 構築された経験則がありこれらの禁則に抵触しない ようにしなければならない. 企業内の経験則は明示さ れず, 個人のノウハウになっている場合も多い. この ような場合, 設計者が希望する対策は, 大変更となり やすい最小重量設計ではなく, なるべく少ない変更で 対処できる案を元に検討することである.

本稿のような場合に試行できる手法の一つとして擬 似最小 2 乗法による方法が提案されている ${ }^{(3)}$. (4).この 手法は, 最小重量を狙ったものではなく, 設計変数空 間において変更量ベクトルの長さを最小として制約条 件を満足する構造变更を行う. 本稿では, 擬似最小 2 乗法による応力低減を簡単な構造である片持梁に始め て適用し, 次に実際の大型送風機用羽根車に適用し, 問題解決を図る. 


\section{2. 做小莗裂発生現泉の追求}

遠心力による荷重条件が最も箃しい, という経験則 があり，設計する場合には従来の計算方法により遠心 力に起因する応力の検討が行われていた. また, 文献 (ク (9)には有限要素法による計算例もあるが，モデル化 は羽根部だけであり，構造物全体の挙動はまだ公にな っていない． 有限要素により回転軸に取付けられる円 盤状の羽根車全体のモデル化を行い，挙動を調べる.

2-1 喜心かによる応力の缇来からの計算方法 羽根 車を回転円板とし，応力は回転軸からの距離のみの関 数と考え, 微小容積に作用する力の平衡式から, 応力 と変位に関する微分方程式を立てることができる. 複 雑な形状の羽根車を多数の厚さ一様な輪で置き換え, この式を利用して図式計算法で解くドナートの方法, これを改良したホッジの方法が知られている(ら). 主板 およひ側板の岡性を考慮した羽根部の応力計算法とし ては, 主板, 側板, 羽根部をラーメン構造とし, 同一 モーメントが各部に作用するとして応力比を求める解 法が知られている(6).しかし，いずれの方法も，実際 の形状を単純化するため, 羽根部と主板, 側板結合部 分の応力を正確には算出できなかった.

有限要素法による応力計算も行われており, 羽根部 のモデル化と応力発生メカニズムの解明を行っている (. また, 応力低減のための構造最適化も試行されて いる(8) (9). しかし，モデル化は羽根部だけであり，全 体の変形を把握していない，本論文で対象とする主板， ブレード, 側板から構成される羽根車の遠心力による 応力発生メカニズムを解明し, その応力を工業的有用 に低減した例はまだ公になっていない.

$2 \cdot 2$ 有限要素によるモデル化と各部の名称 図 1 に計算で用いた羽根車の有限要素モデルを示す. 形状 変更を容易にするために，3 次元 C ADで形状を作成 し, 自動有限要素モデル化ソフトを使用して 4 面体要 素でモデル化した. 計算精度を上げるためアイソパラ メトリック 2 次要素に変換してある. 要素数は 79,486 , 節点数は 157,931 であり，これで回転する羽根車全体 をモデル化できたことになる. 図 1 は羽根車を側板側 から見た図であり，側板中央部分に空気吸入口が見え る. 周辺の隙間から空気が排出される. 側板中央部分 の空気吸入口から湾曲したブレードと主板の一部が見 える. 主板中央には回転軸に取りつけるためのボスが あり，ボスの内径を固定して遠心力による荷重を各接 点に加えて変形と応力を計算した. 図 1 の外周部を拡 大して図 2 に示す. 羽根車は円錐型の側板, 空気を加 速するための湾曲したブレード（羽根部），平らな円
板の主板という3 個の部品から構成されており，各部 品は溶接により結合されている. 亀裂はこの外周部の 側板とブレードの結合部分に発生した.

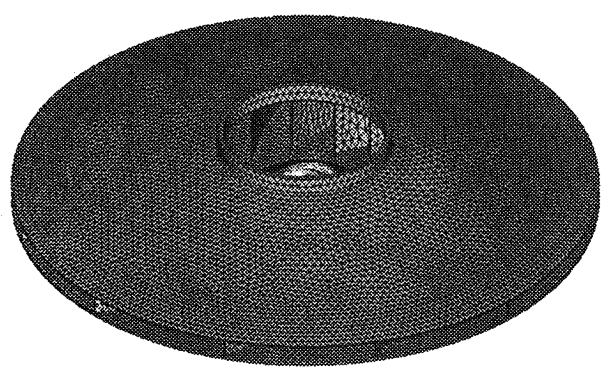

Fig.1 FEM model of impeller 157,931 grid points and 79,486 elements

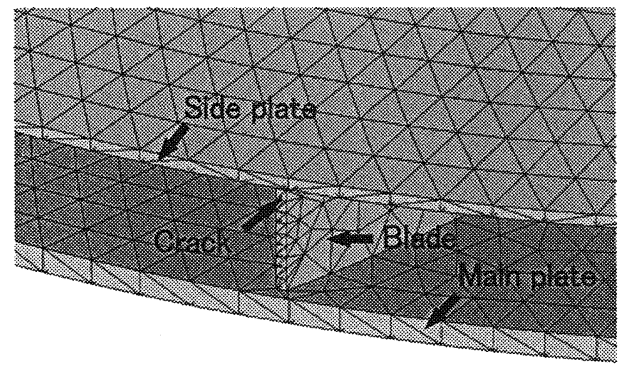

Fig.2 Names of 3 parts and crack position

2.3 有限要素法による計算結果 図 1 に示すモ デルの中心を拘束し，遠心力を与えた場合の変形を図 3 に示す. 遠心力により, 羽根車全体が図上方の側板 側に持ち上がると同時に側板が大きく波打っている. 図 4 に図 3 の外周部分桩大図を示す. 図 2 と比較すれ ば，側板が大きく波打っているために，ブレードが傾 き, ブレードの主板と側板との外周結合部分に高い応 力が発生することが分かる. 図 4 では色の濃淡で第 1 主応力の大きさを表している.この図では隠れている が, ブレードと側板との結合部分にも，高い応力が発 生している．側板が波打つことから，この現象は実際 の計算担当者らによってウェーブ現象と命名された. この現象は，今回の計算によって初めて明らかになっ たものであり，外周部の実際の亀裂現象と運転時の応 力測定結果を解明するものとして，現場の人々に感嘆 と有用な示唆を与えた．また，高温雲囲気内で長時間 稼動した羽根車の中には, ウエーブ現象のように側板 が永久変形したものもある，とのことである. 
従来の計算によると最大応力值はブレードの中央の 位置に発生するはずであるが，実際には結合部分に亀 裂が発生する. 従来の計算方法は主板と側板を単純支 持した状態で計算しており, ウェーブ現象を考慮して いないためと考えられる.

有限要素法によって得られた最大応力の発生場所は, 主板とブレードとの結合部であり, 次の高応力部位は 側板とブレードとの結合部である. 実際の亀裂部(図 2) は側板とブレードとの結合部で, 最大応力部とは異 なる. この原因として, 羽根車の製作過程では, 主板 とブレードをまず溶接し，次に側板を溶接する．側板 溶接時には狭い隙間で溶接する必要があり, 溶接場所 が構造的に弱くなったためと考える.

以上の結果から, 遠心力が原因で側板が波打つ現象 (ウェーブ現象)が発生し, 主板・側板とブレードとの 結合部に高応力が発生すると考えられる.また,この 現象が羽根車の亀裂の主原因になっていると考えられ る.

2.4 固有モードによる応力分布計算結果 有限要 素法による固有值解析を行った結果, 1 次固有振動数 は $38.8 \mathrm{~Hz}$ であり, 図 5 に固有モード形状, 図 6 に最 大応力が発生する主板中央のボス付近の応力分布を濃 淡で示す. 図 5,6 から判断すれば, 外周部付近に発 生した亀裂部(図 2) とは異なる現象である. 2次固有 振動数 $39.0 \mathrm{~Hz}$ の固有モードは, 構造物が対象であるた めに 1 次固有振動数と同じモード形状で, 傾く方向が 90 度異なるだけである. 3 次固有振動数 $96.7 \mathrm{~Hz}$ は本 研究で用いた羽根車の稼働回転数とは大きく異なるた め共振しないと考えられる. 以上の結果より, 羽根車 の亀裂の原因は運転時における共振現象によるものと は考えにくい.

2.5 実際の連転中における応力測定 次に計算値 との比較をするため破損インペラと同一品において, 実際の運転中の応力測定を実施した. 羽根車各部に歪 ゲージを接着し，スリップリングを介して回転軸から 測定のためのリード線を引き出して行った. 表 1 に計 算と歪ゲージを用いた実験值との比較を示寸. 亀裂箇 所と最大応力籄所で応力の実測值と計算值はほぼ一致 しており，よく現象を表していると考えられる.

図 7 に刍裂起点該当位置における実際の運転中の始 動から始動完了までの歪みアナログデータを代表例と して示す. この図から, 回転数が増加するに従って応 力が増加する. 30 秒後に一定回転に達した後, わずか に変動応力が発生しているとも見えるが, 回転上昇に よる雑音の影響もあり, 明確ではない. 測定応力の主 体は, 回転に伴って上昇する応力であり, 応力值を計
算結果が説明できることから遠心力によるものと思わ れる.

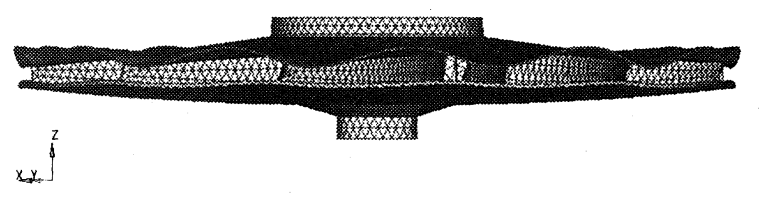

Fig.3 Deformation of impeller by centrifugal force

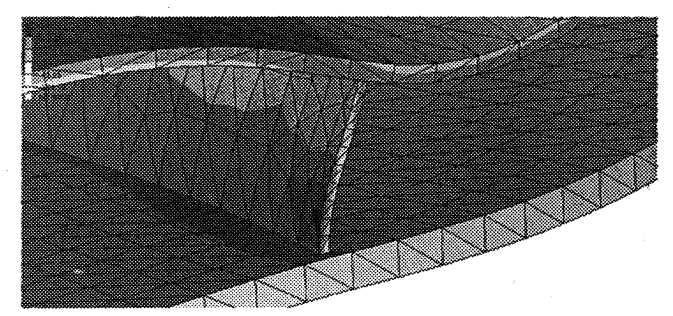

Fig.4 First principal stress by centrifugal force

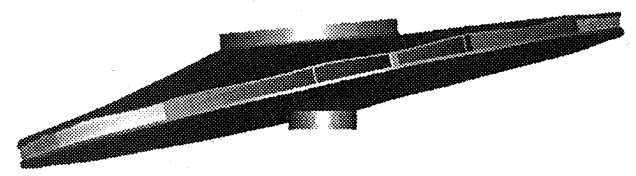

Fig.5 Mode shape of first natural frequency $(38.8 \mathrm{~Hz})$ by FEM

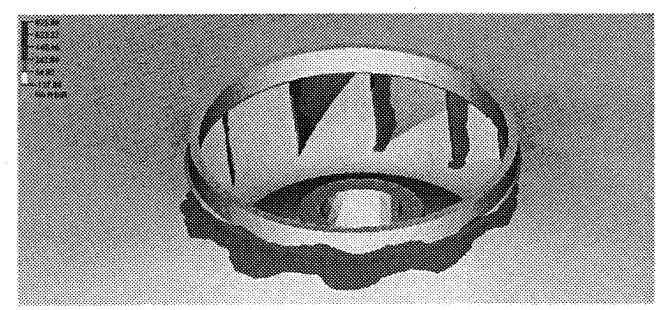

Fig.6 Stress of first natural frequency $(38.8 \mathrm{~Hz})$ by FEM

Table.1 Comparison of calculation and experiment

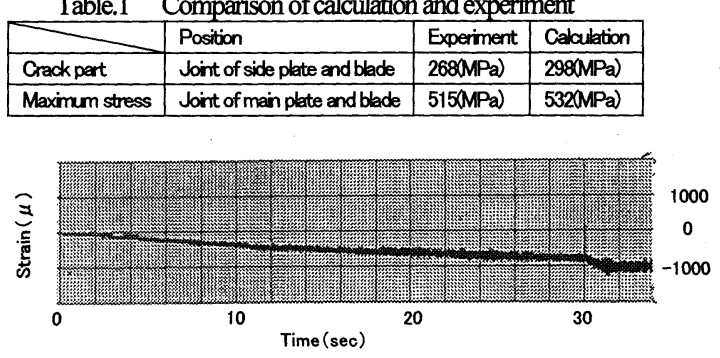

Fig.7 Measured strain in the rotation of impeller 
3. 拟似最小二乗法による構造变更

前章より, 羽根車の亀裂原因は, 遠心力によるウェ 一ブ現象と考えられる. 擬似最小 2 乗法による構造変 更手法を応力制約条件に始めて適用するために, 単純 な片持ち梁に適用して有効性を検討した後, 主板とブ レードとの結合部に発生した最大応力に着目し応力の 低減を狙った構造変更を試みる，亀裂は 2 番目の高応 力部位である側板とブレードとの結合部に発生したが, 設計者と協議した結果，実験でも確認された最大応力 部位の方が重要である, となった.

3.1 棈造变更方法 設計変数を板厚 $t$ とし, 板厚 に関する応力の感度 $\partial \sigma / \partial t$ を求め, 擬似最小 2 乗法 を用いて構造変更を試行する. 設計変数変更後の応力 值は次のように線形予想される.

$$
[z]\{\Delta t\}=\{\Delta \sigma\}
$$

$[z]$ : 感度マトリックス $z_{i j}=\partial \sigma_{i} / \partial t_{j}$

$\{\Delta t\}$ : 設計変数の変更ベクトル

$\{\Delta \sigma\}$ : 応力值の変更ベクトル

感度マトリックス $[z]$ は列数が設計変数の数で行数 が対象としている応力の数である.

有限要素法の場合, 一般に要素の数は大きくなり数 十万の規模となることもある. それに対し，問題とす る応力は数個とする. ここで, 設計変数として各要素 の板厚を, また挙動制約条件として最大応力だけを選 ベば， [z]は行ベクトルとなる.

感度マトリックス $[z]$ と応力変更量 $\{\Delta \sigma\}$ が与えら れるとき, 式(1)から設計変数の変更ベクトル $\{\Delta t\}$ を 求める. 式(1)は式の数より変数が多い方程式となり, 無数の解 $\{\Delta t\}$ が存在するが, $\{\Delta t\}$ のノム最小の条件 を付加すると $\{\Delta t\}$ は一意に求まり，

$$
\left\{\Delta t^{*}\right\}=[z]^{T}\left([z][z]^{T}\right)^{-1}\{\Delta \sigma\}
$$

となる.

式(2)は擬似最小 2 乗法として知られているが，式 (1)の条件下で $\{\Delta t\}^{T}\{\Delta t\}$ を最小にする $\left\{\Delta t^{*}\right\}$ を直接求 めることによっても導くことができる. $\{l\}$ をラグラ ンジュ末定乗数ベクトルとしてラグランジュ関数 $H$ を

$$
H(\{\Delta t\},\{l\}) \equiv \frac{1}{2}\{\Delta t\}^{T}\{\Delta t\}-([z]\{\Delta t\}-\{\Delta \sigma\})^{T}\{l\}
$$

とすれば式(1)の条件下でラグランジュ関数 $H$ を最小 にする $\{\Delta t\}$ を求めればよい

$$
\frac{\partial H}{\partial\{\Delta t\}}=\{0\}
$$

より

$$
\{\Delta t\}=[z]^{T}\{l\}
$$

式（5）を式（1）に代入して

$$
[z][z]^{p}\{l\}=\{\Delta \sigma\}
$$

$[z][z]^{T}$ の逆行列が存在すれば, ラグランジュ未定乗数 ベクトル $\{l\}$ は

$$
\{l\}=\left([z][z]^{T}\right)^{-1}\{\Delta \sigma\}
$$

式(7)を式(5)に代入して式(2)を得る. 式(2)の計算実 行において, 要素の数がいかに大きくても， $[z][z]^{T}$ は挙動制約条件数の行列に縮小され、要素数によらず 短い計算時間で可能である.

3.2 片持ち梁の满造変更擬似最小 2 乗法を応 力制約条件に適用する. まず簡単な構造物である片持 ち梁に適用して，その有用性を検討する．諸元を図 8 に示す. 梁の先端に荷重 $1.0 \mathrm{~N}$ を加え, 他端を固定す る. 構造変更に用いた片持ち梁の有限要素法モデルを 図 9 に示す. 使用した有限要素法モデルはすべて板要 素であり, その板要素全部の板厚を設計変数とした. 設計変数の数（要素数）は 500 で, 節点数は 561 であ る. 変更量は変更前の板厚の $10 \%$ を最大として繰り返 し計算を行った.

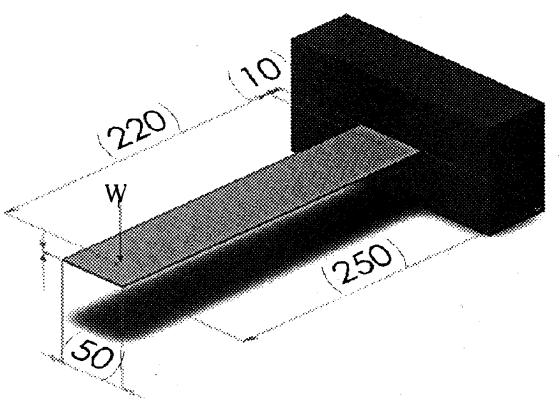

Fig.8 Cantilever model (W: force, $1.0 \mathrm{~N})$ 


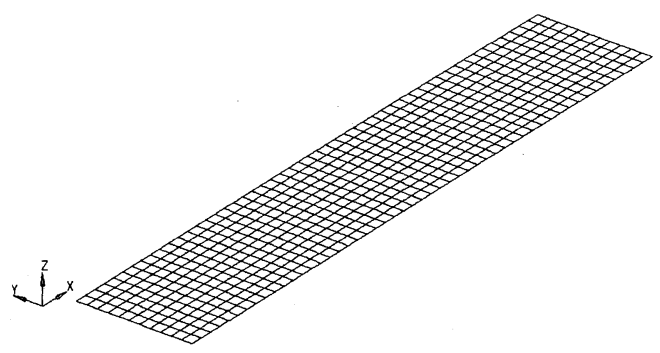

Fig.9 FEM Model of cantilever

計算の結果, 最大応力は固定端側の端部の中央部分 であり，31MPa であった. この最大応力を制約条件と し, $31 \mathrm{MPa}$ から約半分の $15 \mathrm{MPa}$ に変更するための構造 変更を試行する. 図 10 に示すように 5 回の構造変更 により注目した端部中央要素の応力を目標の $15 \mathrm{MPa} に$ 下げることが出来た. 構造変更に伴う重量の増加は

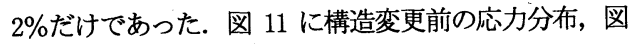
12 に構造変更後の応力分布を濃淡で示す. 構造変更前 の応力分布と比較すると、注目した要素の応力を下げ ることが出来てはいるが, 最大応力の発生する場所が 変化し, 最大応力值はむしろ増加している. 図 13 に 構造変更化後の板厚の分布を濃淡で示す. 注目した固 定端の要素は薄くなると同時に, 隣の要素は厚くなり, 固定端の注目した要素に作用する力を分散している. 構造変更は注目した要素付近だけであり, 構造変更に よる重量増加はわずかであるが，有効な応力低減方法 としては採用できないと考える.

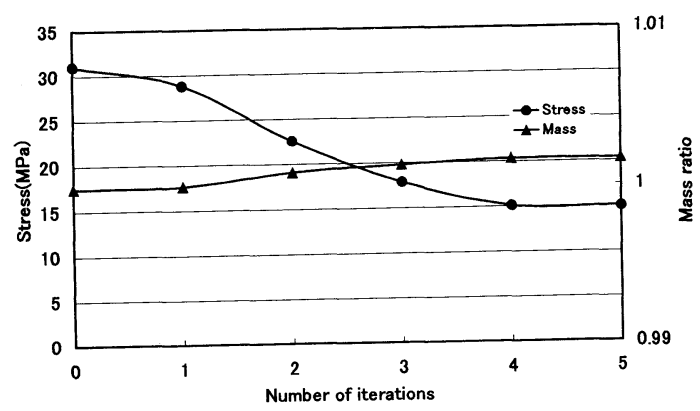

Fig.10 The change of stress and mass in iterations of calculation

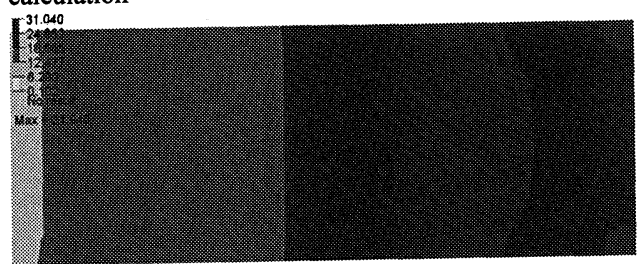

Fig.11 Stress distribution before structure modification (MPa)

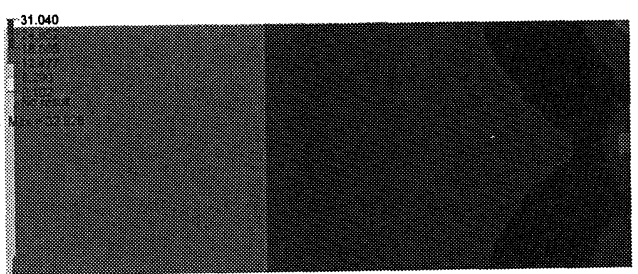

Fig.12 Stress distribution after structure modification (MPa)

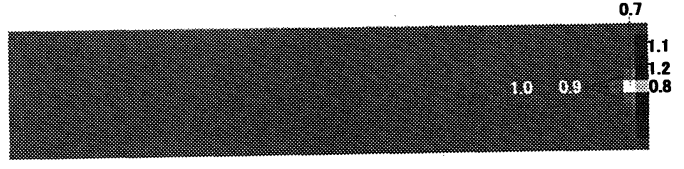

Fig.13 Thickness distribution after the modification (mm)

次に荷重点の変位を $4.8 \mathrm{~mm}$ から $2.0 \mathrm{~mm}$ に変更するた めの構造変更を行った. 荷重点変位の板厚に関する感 度を求め, 式(2)により板厚変更量を算出した. ただ し，ここでは $\Delta \sigma$ は変位変更量になる. 結果を図 14 に示す. 5 回の構造変更で荷重点の変位は $2.01 \mathrm{~mm}$ とな り, 目標を満足した. 重量増加は約 20\%である. 構造 変更後の板厚の分布を図 15 に示す. 固定端中央が最 も厚く, 先端側ほど薄い板厚の分布となった. 応力は 全体が下がり、最大応力点が移動することも無く, 有 効な応力低減方法と考える.

応力は局部的な構造が大きく影響するが，変位はよ り全体的な現象であり, 局所変更解に陥りにくい, と 考える.

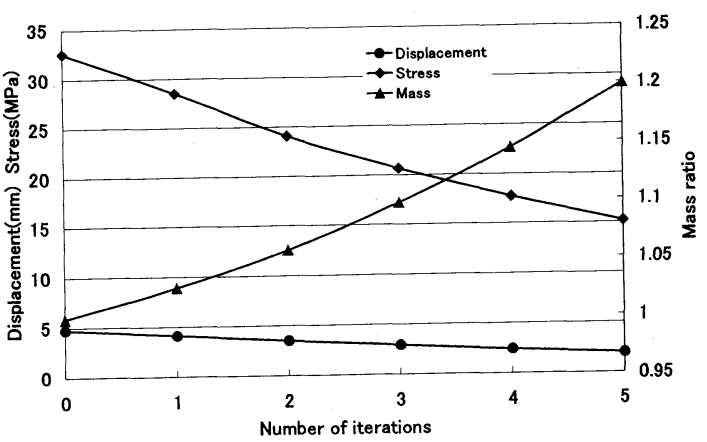

Fig.14 The change of stress and mass in iterations of calculation 


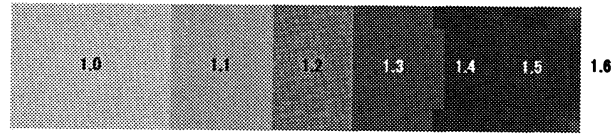

Fig.15 The thickness after the modification $(\mathrm{mm})$

擬似最小 2 乗法では変更べクトルの長さ最小で構造 変更を行う.このような変更量最小を狙う構造変更手 法を最大応力だけを制約条件として適用する場合, 有 効な応力低減方法としては採用できない結果を得る場 合がある. そのような場合，変位を制約条件にすれば よい, と言える.

3.3 大型送風機用羽根車の構造変更 構造変 更に用いた送風機の有限要素法モデルを図 16 に示す. 使用した有限要素法モデルはボス部を除いてすべて板 要素に変更した. 要素数は 41,028 で,節点数は 43,308 である. 今まではアイソパラメトリック 4 面体 2 次要 素によりモデル化していたが, 設計変数を板厚にして 構造変更を行うためである. 要素を 4 辺形 1 次板要素 にすると最大応力場所は同じであるが計算最大応力值 は 746MPa となった. 表 1 と比較すると, アイソパラメ トリック 4 面体 2 次要素の方が実験とよく一致してい る.

今回は，実験と計算で共に主板とブレードとの結合 部に最大応力が発生しているので，これを制約条件と し, 最大応力が $746 \mathrm{MPa}$ から 400MPa に低下するように 擬似最小 2 乗法を用いて構造変更を行う. 側板, ブレ 一ド，主板は板材を加工して製作するので，均一厚さ が望ましい. また, 片持梁の結果から全板要素の板厚 を設計変数にすると実用的でない解が得られているこ とから, 側板, ブレード, 主板の板厚 3 個だけを設計 変数とした. これは, 設計変数をグループ分けして, そのグループでは同一の厚さにする，という側面制約 条件を設計変数に設定することになる. 繰返し計算を 行った結果を図 17 に示す. 10 回の計算で送風機の最 大応力は 401MPa となり目標をほぼ満足した. 重量増加 は約 $10 \%$ であった. 構造変更後の遠心力による変形を 図 18 に, 応力分布を図 19 に示す. 最大応力の移動も なく, 亀裂部の応力も同時に低減できた. 最も小重量 のブレードが約 2 倍の板厚になったが, 最も重い主板 が約 3\%薄くなった結果, 全体の重量増加は約 $10 \%$ に 止まっている. これは, 従来の実機の主板は不必要に 厚く設計されていたことを示しており, 主板に軽量化 の可能性があることが判明した。
次に, 参考として, すべての板要素の板厚を設計変 数とし, 構造変更を行った. 計算に使用した有限要素 法モデルは計算時間の関係上，図 16 のモデルよりも メッシュの粗いものとした. 設計変数の数 (要素数) は 5,112 で, 節点数は 5,004 である.

この有限要素法モデルを用いて繰返し計算を行った 結果, 3 回の計算で着目した接点の応力は $392 \mathrm{MPa}$ とな った. 図 21, 図 22 に示すように最大応力の発生した 要素付近だけ板厚の変更が行われ, その結果, 着目し

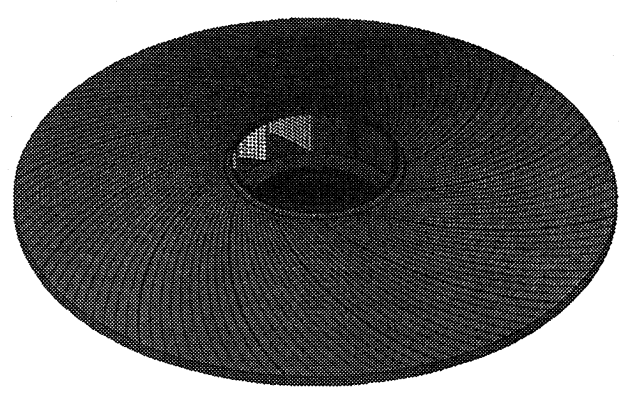

Fig.16 FEM Model by shell ekements

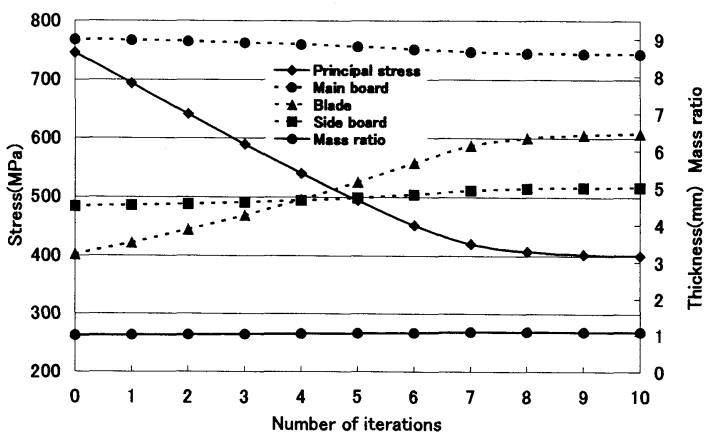

Fig.17 The change of stress and thickness in iterations of calculation (design variables are the board thicknesses of 3 components)

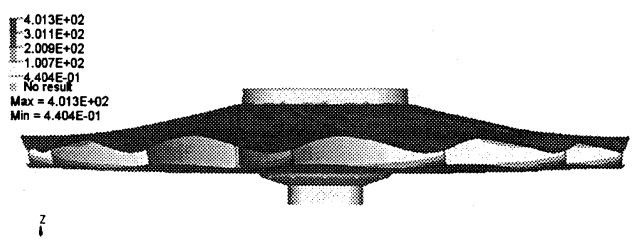

Fig.18 Deformation by centrifugal force (after modification) 


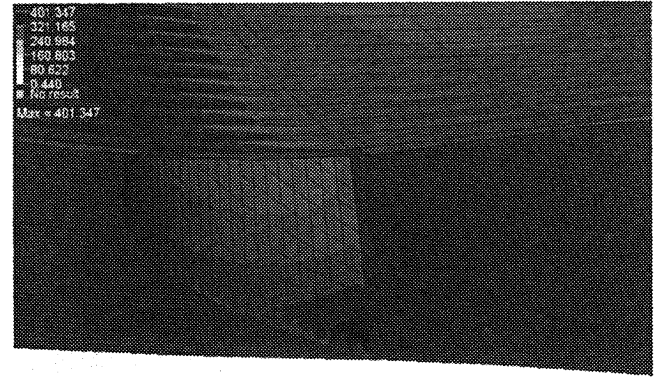

Fig.19 The simulation result by centrifugal force (A design variable is the board thickness of 3 components)

た要素の応力を低減することができた．次に，図 21 に示す 1 個の結合部だけの変更を全体に反映させた図 22 のように変更したモデルを作成し，計算を行った. その結果, 着目した要素にかかる応力はすべて $392 \mathrm{MPa}$ と低减していることが判明した. しかし, 図 24 に示 す隣接する接点位置に最大応力が移動し, 応力值は 576MPa となった. 最大応力の位置が移動すること,お よび, ブレードの局部的な板厚変更は製造上無理なこ とから,この構造変更は, 对策案としては採用できな かった.

\section{4. 結論}

本研究では, 実際の稼動中に微小亀裂が検出された 大型送風機用羽根車の亀裂原因を調查するために有限 要素法によるモデル化, 固有モード形状に変形する場 合の応力分布, 遠心力による変形と応力分布の計算を 行った. その結果, 羽根車の亀裂原因は共振現象によ るものとは考えにくいことが判明した.

羽根車全体をモデル化し，遠心力による変形の計算 を行うことにより，側板のウェーブ現象が初めて認識 され，これによりブレードが傾くことにより，従来の 方法では分からなかった溶接場所に最大応力が発生す ることが判明した. ウエーブ現象による応力分布は実 機稼動中の応力測定結果を裏付けることができた.

次に, 最大応力を少ない変更量で低减するために, 擬似最小 2 乗法を初めて応力問題に適用した. まず, 簡単な梁モデルを用いて有効性を検証した結果, 挙動 制約条件を固定端中央の応力とした場合は, 構造変更 場所は最大応力部位付近だけになり, その周辺が厚く, 注目する場所は逆に薄くなる結果が得られた. 同時に, 最大応力点の移動が見られ，対策案としては採用でき ない結果を得た。

挙動制約条件を荷重点の変位とした場合は最大応力 の移動は見られず,全体の応力を低减することができ
た. 板厚分布は固定端ほど厚く, 自由端ほど薄くなる 結果が得られた.

次に, 羽根車の亀裂を防止するための構造変更を行 った. 設計変数を 3 部品 (主板, ブレード, 側板)の板 厚とし, 挙動制約条件を最大応力として擬似最小 2 乗 法を適用した結果, 10 回の繰返し計算で最大応力は 746MPa から 401MPa となり, 最大応力点の移動もなく応 力値を目標值まで低減することができた，また，亀裂 部の応力も低減することができ, 問題解决のための有 用な構造を提案することができ, 主板に軽量化できる 可能性があることが判明した.

設計変数を全ての板要素の板厚とし計算を行った結 果, 着目した要素の応力は低减できたが最大応力の場 所が移動し，実際に製造困難な形状を得た.

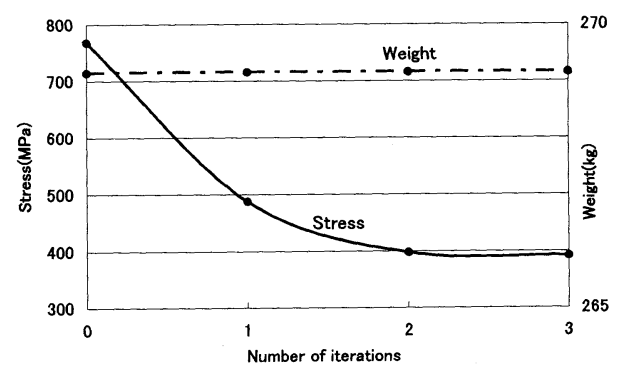

Fig.20 Calculation result (A design variable is the board thickness of all elements)

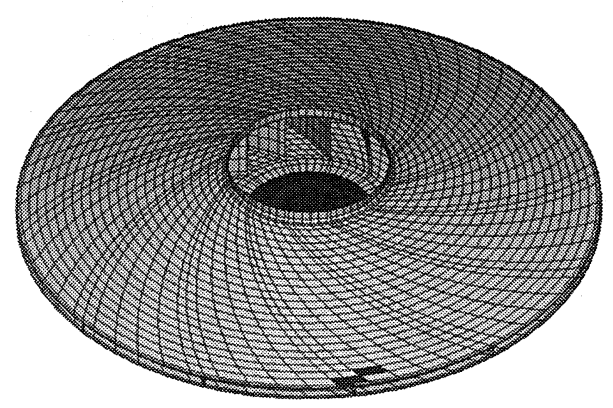

Fig.21 Structure change of board thickness by FEM (A design variable is the board thickness of all elements) 


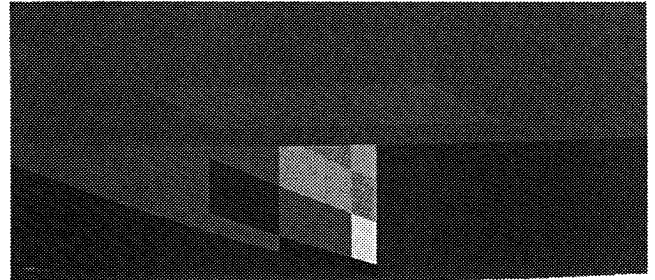

Fig.22 Structure change of board thickness by FEM (A design variable is the board thickness of all elements)

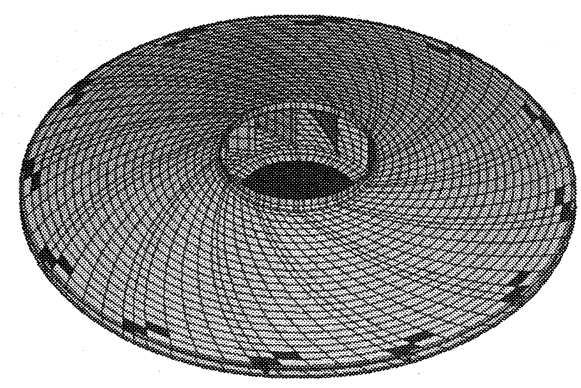

Fig.23 Structure change of board thickness by FEM (A design variable is the board thickness of all elements)

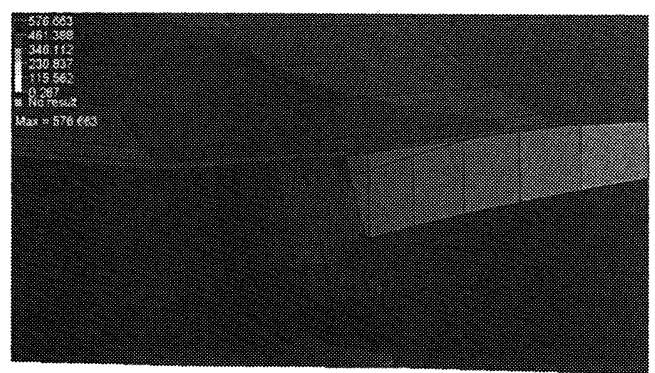

Fig.24 The simulation result by centrifugal Force (A design variable is the board thickness of all elements)

\section{文献}

(1)O.C.Zienkiewicz, The finite element method in engineering science, (1971), McGra-Hill.

(2)MSC.Nastran Japanease Online Manual, (2001), MSC Software.
(3) Iwahara, M., Nagamatu, A., Transactions of the Japan Society of Mechanical Engineers, Series C, Vol.56, No.523, (1990-3), pp.86-92.

(4) Iwahara, Sakamoto, Matsuuki, Tanaka, Nagamatsu, A New Method for Car Body Design Optimization, SAE Paper 911074.

(5)Oonishi, Turbo machine, Vol.2, No.2(1974-5), pp.11-16.

(6)Ikui, Inoue, Ta-bo sofuki to assyukuki, (1988), Corona publishing Co. LTD., pp.753-754.

(7)Yamamoto et al., Transactions of the Japan Society of Mechanical Engineers, Series A, Vol.59, No.567, (1993), pp. 304-311.

(8)Kaneko et al., Transactions of the Japan Society of Mechanical Engineers, Series A, Vol.319, No.324, (1991), pp. 319-324.

(9)Koo et al., Proceedings of Regular Meeting of the Japan Society for Computational Engineering and Science, Vol.6(2001-5), pp.165-168. 